\title{
METHODOLOGY FOR NON-DESTRUCTIVE IDENTIFICATION OF THICKNESS OF UNILATERALLY ACCESSIBLE CONCRETE ELEMENTS BY MEANS OF STATE-OF-THE-ART ACOUSTIC TECHNIQUES
}

\author{
Krzysztof SCHABOWICZ \\ Institute of Building Engineering, Wroctaw University of Technology, Wybrzeże Wyspiańskiego \\ 27, 50-370, Wroctaw, Poland
}

Received 6 Oct. 2012; accepted 6 Dec. 2012

\begin{abstract}
The paper presents a methodology for comprehensive use of ultrasonic tomography and impact-echo - the state-of-the-art acoustic techniques - for non-destructive identification of the thickness of unilaterally accessible concrete elements. Since the techniques are not commonly used, they are little known. Therefore, a brief description of the techniques is given to facilitate the understanding of the subsequently presented methodology. The article gives a practical example of the use of the methodology, which demonstrates its suitability for non-destructive identification of the thickness of concrete elements, particularly those only accessible from one side. In the example, the concrete shell of a heat pipe, carrying tunnel located under a river was tested using the ultrasonic tomography and impact-echo techniques. The tests were carried out according to the proposed methodology. It should be noted that the test results yielded by the two methods were similar. In this way, the proposed methodology has been validated.

Keywords: concrete; ultrasonic tomography; impact-echo; non-destructive identification; ultrasounds.

Reference to this paper should be made as follows: Schabowicz, K. 2013. Methodology for non-destructive identification of thickness of unilaterally accessible concrete elements by means of state-of-the-art acoustic techniques, Journal of Civil Engineering and Management 19(3): 325-334.
\end{abstract}

\section{Introduction}

In building practice, it is often necessary to determine the thickness of a concrete element accessible from one side only. Because of the location of the structure to be tested, it is not always possible to carry out destructive (e.g. drilling) tests. Destructive testing is ineffective when not only the thickness of unilaterally accessible concrete elements, but also the distribution of thickness along the structure or within a larger area of the latter needs to be determined. If such an element (a foundation slab, a wall, a sewer or tunnel shell, etc.) is in contact with, e.g. water, destructive testing is out of question.

In the author's opinion, it is worthwhile to use non-destructive techniques to determine the thickness of unilaterally accessible concrete elements since such non-invasive tests can be carried out in any number of places. The ultrasonic tomography and impact-echo techniques are suitable for this purpose (Gorzelańczyk et al. 2012a, b; Gorzelańczyk, Schabowicz 2012; Hoła et al. 2008, 2011; Hoła, Schabowicz 2010; Schabowicz, Hoła 2012). Although these acoustic techniques (Hoła, Schabowicz 2010; Gorzelańczyk 2011, 2012; Goszczyńska et al. 2012; Hoła, Schabowicz 2010; Stawiski
2012) have been described by Samokrutov and Shevaldykin (2011), Shevaldykin et al. (2003) and Sansalone and Strett (1997) and in reports (ACI 228.2R-98 1998; Bundesanstalt für Straßenwesen 2001; ASTM C1383-04 2010), no methodology for their comprehensive (in the sense that the results of tests carried out using one of the techniques are subsequently verified by the results obtained by the other technique) use has been developed. The comprehensive approach is necessary especially when it is impossible to verify the test results in a destructive way. This paper proposes such a methodology and presents its practical verification.

\section{Survey of literature}

The identification of the thickness of concrete elements, especially the unilaterally accessible ones, has been the subject of studies by Bishko et al. (2008), Kozlov et al. (1997), Samokrutov et al. (2002, 2006), and Samokrutov and Shevaldykin (2011). The researchers proposed to determine the thickness of such elements, using the ultrasonic echo technique. Taffe and Wiggenhauser (2006) proposed to use the impact-echo technique for

E-mail: k.schabowicz@pwr.wroc.pl 
this purpose, and so did Krause et al. (2005) and Garbacz and Piotrowski (2010). Bishko (2007) recommends the state-of-the-art ultrasonic tomography technique for determining the thickness of unilaterally accessible concrete elements. Since this technique is new, so far its use has been limited, and very few studies have been undertaken.

The successful application attempts undertaken, by the above researchers, each time involved only one non-destructive testing technique. It is hard to find cases in which two non-destructive techniques, e.g. ultrasonic tomography and the impact-echo technique, were jointly used to identify the thickness of unilaterally accessible concrete elements. Garbacz (2005) and Kurz et al. (2012) were the first to use the techniques in a complementary way, employing an automatic multisensor testing system for this purpose. Their studies, however, did not deal directly with the determination of thickness but with the evaluation of the condition of a structure made of reinforced concrete.

On the basis of their own experience (Gorzelańczyk et al. 2012a, b; Gorzelańczyk, Schabowicz 2012; Hoła, Schabowicz 2010; Hoła et al. 2011 and Schabowicz, Hoła 2012) have come to the conclusion that when jointly used, the non-destructive ultrasonic tomography technique and the impact-echo technique complement each other, and so ensure more effective identification of the thickness of unilaterally accessible concrete elements. It should be noted that in the case of the ultrasonic tomography technique, the measuring place for a single application of the testing antenna covers an area of $100 \times 500 \mathrm{~mm}$ at a thickness estimation accuracy of a few millimetres. Thus such single measuring places can make up a $500 \mathrm{~mm}$ wide and as much as a few metres long measuring band. This means that using this technique one can test large, flat surfaces and identify the thickness of a concrete element within a large area. In the case of the impact-echo technique, the distance between measuring places is no more than $100 \mathrm{~mm}$. For this reason, this technique is labour-intensive when used to test large structures. But it can be complementary to ultrasonic tomography and can be used to verify the latter's results in randomly selected points. The nondestructive testing by these techniques can be easily automated by mounting the testing equipment on a special scanner or robot (Kurz et al. 2012).

Taking the above observations (supported by the author's experience in this field) into consideration, this paper presents a methodology for the non-destructive identification of the thickness of unilaterally accessible concrete elements through the comprehensive use of ultrasonic tomography and the impact-echo technique. The methodology is based on the investigations carried out by the author using the two techniques (Gorzelańczyk et al. 2012a, b; Gorzelańczyk, Schabowicz 2012; Hoła et al. 2008; Hoła, Schabowicz 2010; Schabowicz, Hoła 2012).

Considering that the two techniques are not commonly used for testing, whereby they are less familiar to the readers, they are briefly described below to facilitate the understanding of the proposed methodology. Also an example of the practical use of the methodology is provided.

\section{Brief description of used techniques}

\subsection{Ultrasonic tomography technique}

This technique is based on the excitation of an elastic wave in the element being tested. A multi-head antenna (incorporating a few tens of independent ultrasonic heads (probes)) is the exciter. It also receives and processes the ultrasonic signals. The heads generate $50-\mathrm{kHz}$ ultrasonic pulses with a maximum range of $2500 \mathrm{~mm}$.

Figure 1 shows an ultrasonic tomograph which includes a multi-head ultrasonic antenna and a laptop with dedicated software enabling the recording of a graphical image in the form of three mutually perpendicular depictions as illustrated in Figure 1.

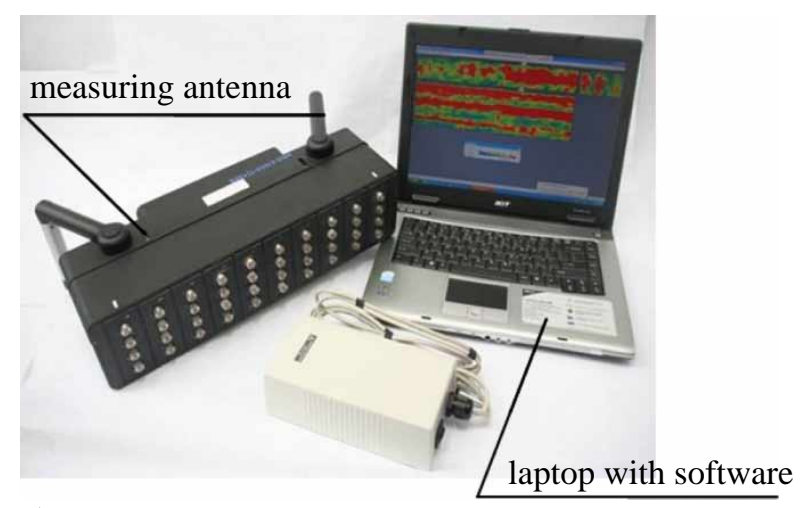

a)

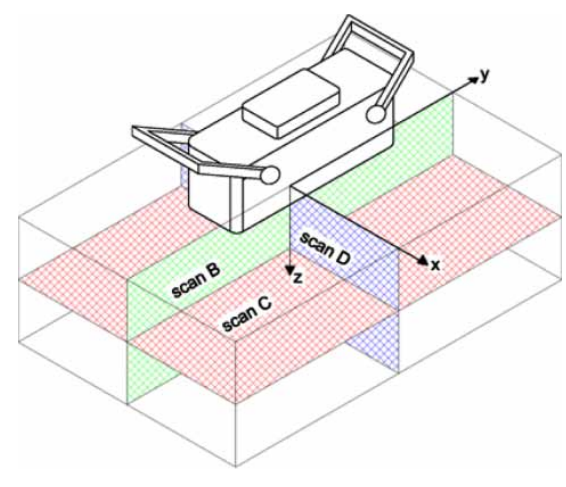

b)

Fig. 1. Ultrasonic tomograph: (a) measuring set; (b) measuring antenna in coordinate system and obtained images 


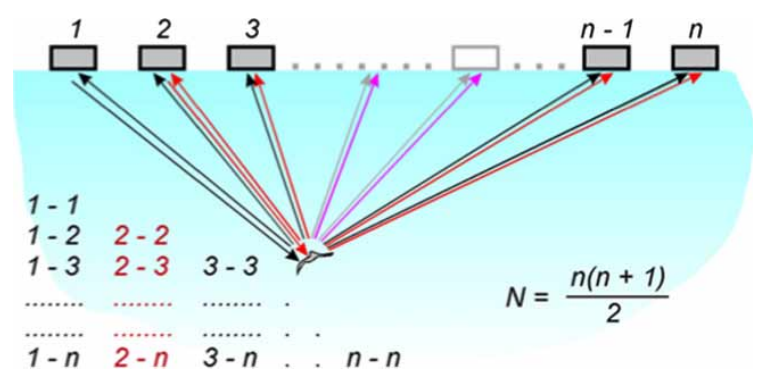

Fig. 2. General schematic of measuring antenna and matrix, illustrating how image is created (Samokrutov et al. 2006)

The advantage of this technique is that no means of coupling the surface of the tested element with the ultrasonic heads is required since dry point contact is used. Another advantage is the fast rate of testing whereby large elements, structures and surfaces can be tested in a relatively short time. As for today, the drawback of this technique is difficulties in interpreting the results due to the small experience of the testers and to the requirement that the minimum size (width) of the tested element should be $500 \mathrm{~mm}$.

Figure 2 shows a general schematic of the measuring antenna and the matrix, illustrating how the images are created. The arrows indicate the propagation of ultrasonic signals from their transmission by a head to their reception by the other heads.

The image in each measuring point is displayed as coloured tomogram $\mathbf{J}$ (described on the basis of Samokrutov and Shevaldykin (2011)) using Eqn (1):

$$
J(x, y)=\frac{1}{N} \cdot \sum_{i=1}^{n} \sum_{j=1}^{n} A\left(Q_{i}, Q_{j}\right) \cdot U_{i j}\left(t_{0}+\frac{r_{i}+r_{j}}{c}\right),
$$

where: $i, j-$ the number of antenna table element transmission and reception; $A\left(Q_{i}, Q_{J}\right)$ - a weight index based on the directions in the table element transmission and reception diagrams; $U_{i j}(t)$ - the signal from $i$ (antenna matrix element transmission) and $j$ (antenna matrix element reception); $t_{0}$ - the hardware delay; $r_{i}$, $r_{j}$ - the distance from the point of sharpness to the

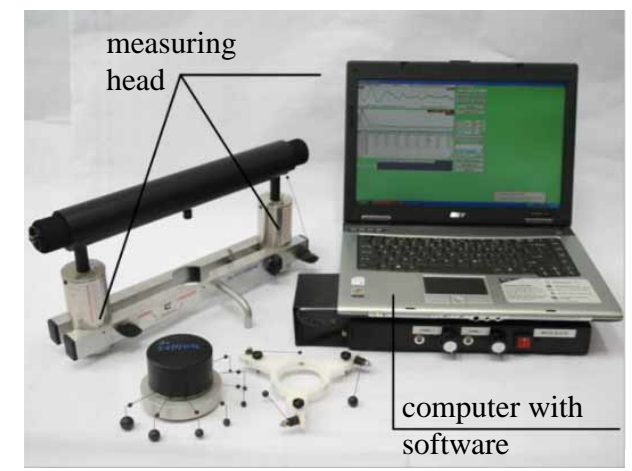

a) transmission and reception of the antenna table elements; $c$ - the ultrasonic speed in the material being tested.

\subsection{Impact-echo technique}

The measuring set used in the non-destructive impactecho technique is shown in Figure 3. It is comprised of measuring heads with exciters in the form of a set of steel balls with different diameters and a laptop. This technique consists in exciting an elastic wave in the tested element by striking its surface with the exciter. The frequency of the generated vibrations ranges from 10 to $150 \mathrm{kHz}$. The dedicated software enables the recording of the graphical image of the elastic wave propagating in the tested element, in the amplitudetime system and the conversion of this image into an amplitude-frequency spectrum by means of the fast Fourier transform or artificial neural networks (Hoła, Schabowicz 2010). The spectrum is subjected to further analysis.

According to Gorzelańczyk et al. (2012a, b), this technique exploits the dependence between frequency $f_{T}$, elastic wave velocity in concrete $C_{p}$ and the depth at which a defect occurs or element thickness $T$, as shown in Eqn (2):

In the obtained amplitude-frequency spectrum, one can distinguish dominant frequency $f_{\mathrm{T} 1}$ corresponding to element thickness. If no defect occurs in the tested element, its thickness $T_{1}$ can be determined on the basis of the amplitude-frequency spectrum and by substituting Eqn (2) into Eqn (3):

$$
\begin{gathered}
f_{T}=\frac{0.96 C_{p}}{2 f_{T 1}} ; \\
T_{1}=\frac{0.96 \cdot C_{p}}{2 \cdot f_{T 1}} .
\end{gathered}
$$

If the surface layer and the base layer are made of different materials with respective thicknesses $T_{3}$ and $T_{4}$, whereby the elastic wave velocity $C_{p 3}$ in the surface

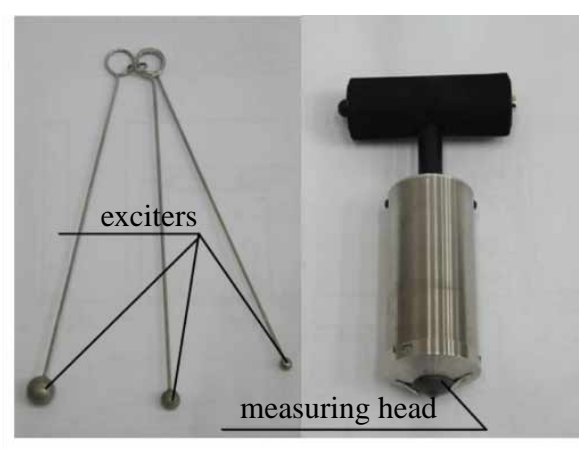

b)

Fig. 3. Idea of impact-echo technique: (a) measuring set; (b) exciters and measuring head 
layer is different from elastic wave velocity $C_{p 4}$ in the base layer, Eqn (2) assumes this form:

$$
f_{T 3}=\frac{1}{\frac{2 \cdot T_{3}}{0.96 \cdot C_{p 3}}+\frac{2 \cdot T_{4}}{0.96 \cdot C_{p 4}}} .
$$

\section{Methodology for non-destructive identification of thickness of unilaterally accessible concrete elements}

The proposed methodology for the non-destructive identification of the thickness of unilaterally accessible concrete elements, using the non-destructive acoustic techniques of ultrasonic tomography and impact-echo in a comprehensive way, is shown graphically in Figures 4 and 5 and described below. Figure 4 presents a general diagram of the methodology, while Figure 5 shows a detailed diagram of the methodology.

It is proposed to carry out the non-destructive identification of the thickness of a unilaterally accessible element in two stages, using the two nondestructive techniques.

In stage 1, tests using the ultrasonic tomography technique should be carried out.

First, $i$ measuring places are selected, and measuring bands are marked. At least one measuring band, with a minimum width equal to the width of the measuring antenna (depending on the type of antenna the width amounts to 380 or $500 \mathrm{~mm}$ ), should be marked in one measuring place. The length of the band may reach a few metres (depending on the memory capacity of the data carrier). The measuring band is made up of $n$ measuring points spaced at every $100 \mathrm{~mm}$. Then the instrument is calibrated by

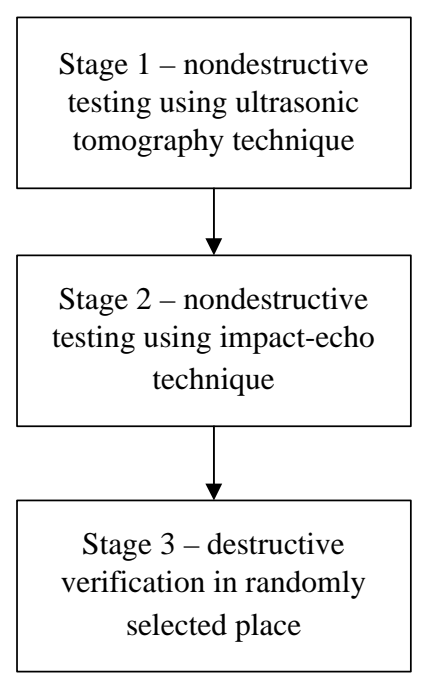

Fig. 4. General diagram illustrating methodology for nondestructive identification of thickness of unilaterally accessible concrete element by means of acoustic ultrasonic tomography and impact-echo techniques

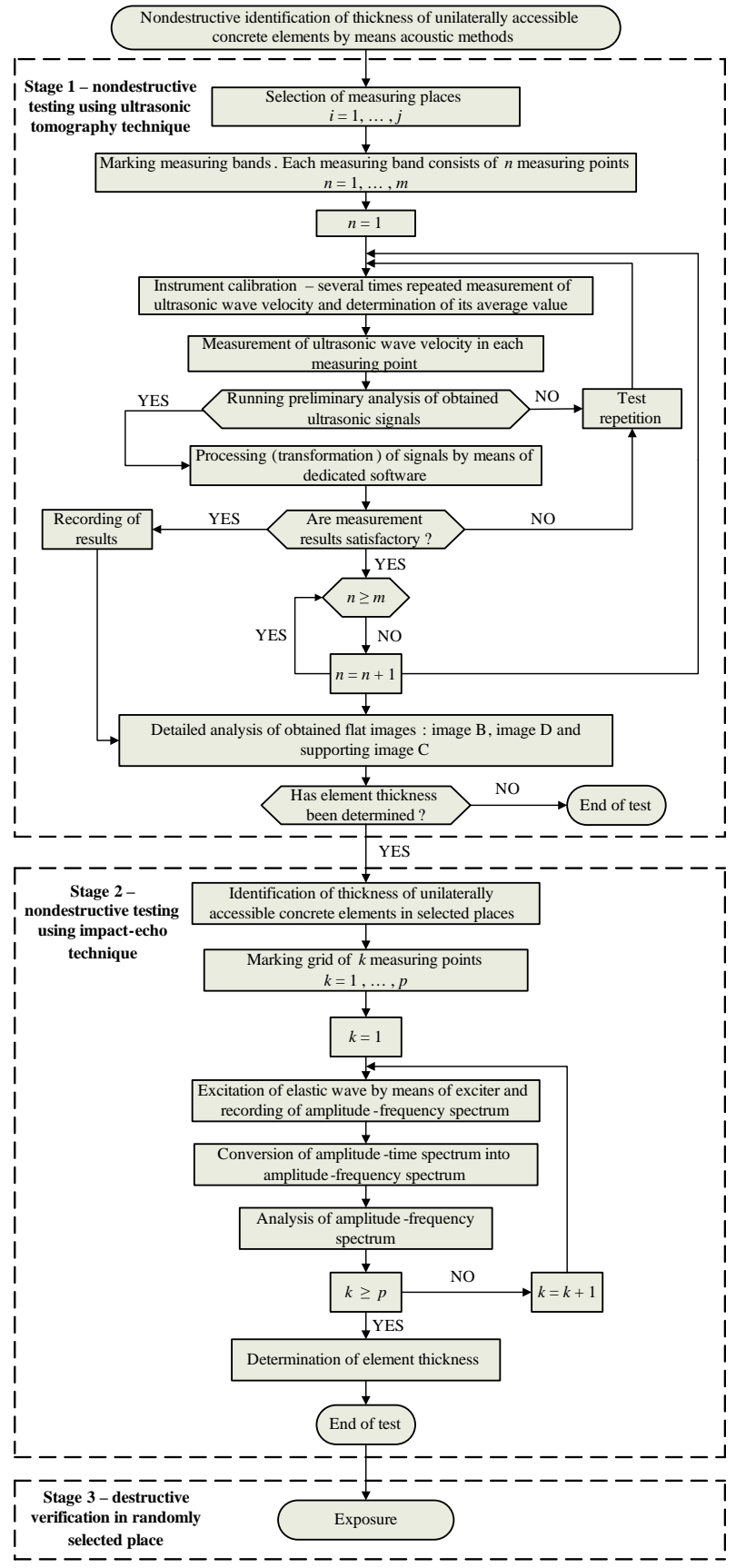

Fig. 5. Detailed diagram illustrating methodology for nondestructive identification of thickness of unilaterally accessible elements by means of acoustic ultrasonic tomography and impact-echo techniques

measuring the ultrasonic wave (signal) velocity in the tested element, and its average value is determined.

Subsequently, the ultrasonic wave velocity should be measured in each of the measuring points. The measurements can be automated by mounting the testing equipment on a special scanner or robot. During each measurement, a preliminary analysis of the ultrasonic signals, consisting in checking whether the element thickness in given measuring point can be determined from the particular measurement is 
carried out. If this is not the case, the test should be repeated. Otherwise, the signals should be processed (transformed) using the dedicated software. The processing consists of assembling the data acquired from the particular measuring points in the given measuring band. If the measurement results are not satisfactory, the test should be repeated. If the measurement results are satisfactory, they should be recorded. As a result, flat images (B, C and D) of the inside of the tested concrete element in three mutually perpendicular directions are obtained, as illustrated in Figure 1. The thickness of the tested concrete element is identified through a detailed analysis of the images, especially images $\mathrm{D}$ and $\mathrm{B}$. Image $\mathrm{C}$ performs a support function, enabling one to correct the results obtained on the basis of images $\mathrm{D}$ and $\mathrm{B}$, by comparing images $\mathrm{C}$ at every millimetre - a few millimetres in the boundary zone of the identified element thickness.

In stage 2, the thickness identified by means of the ultrasonic tomograph is verified to validate the test results obtained in stage 1 . The verification should be done using the impact-echo technique.

First, a grid of $k$ measuring points should be marked in randomly selected measuring places in the measuring bands tested in stage 1. It is recommended that the measuring points should be spaced at no more than every $100 \mathrm{~mm}$ (Hoła et al. 2011). Then an elastic wave is generated in each of the points by means of the exciter, and the amplitude-time spectrum is recorded (Hoła et al. 2011). Subsequently, the spectrum is converted into an amplitude-frequency spectrum by means of the dedicated software using a fast Fourier transform algorithm (Hoła et al. 2011). Then the amplitude-frequency spectrum for each of the measuring points should be analysed to determine the thickness of the tested concrete element.

If possible, in stage 3, the non-destructively identified thickness of the tested element should be verified in a destructive way (through an exposure in a randomly selected place(s)).

\section{Example of practical use of the methodology to test unilaterally accessible concrete shell of heat pipe carrying tunnel}

A heat pipe carrying tunnel under one of the largest rivers in Poland, located at a depth of 10-20 m below the water level, was tested. This more than 900-m-long
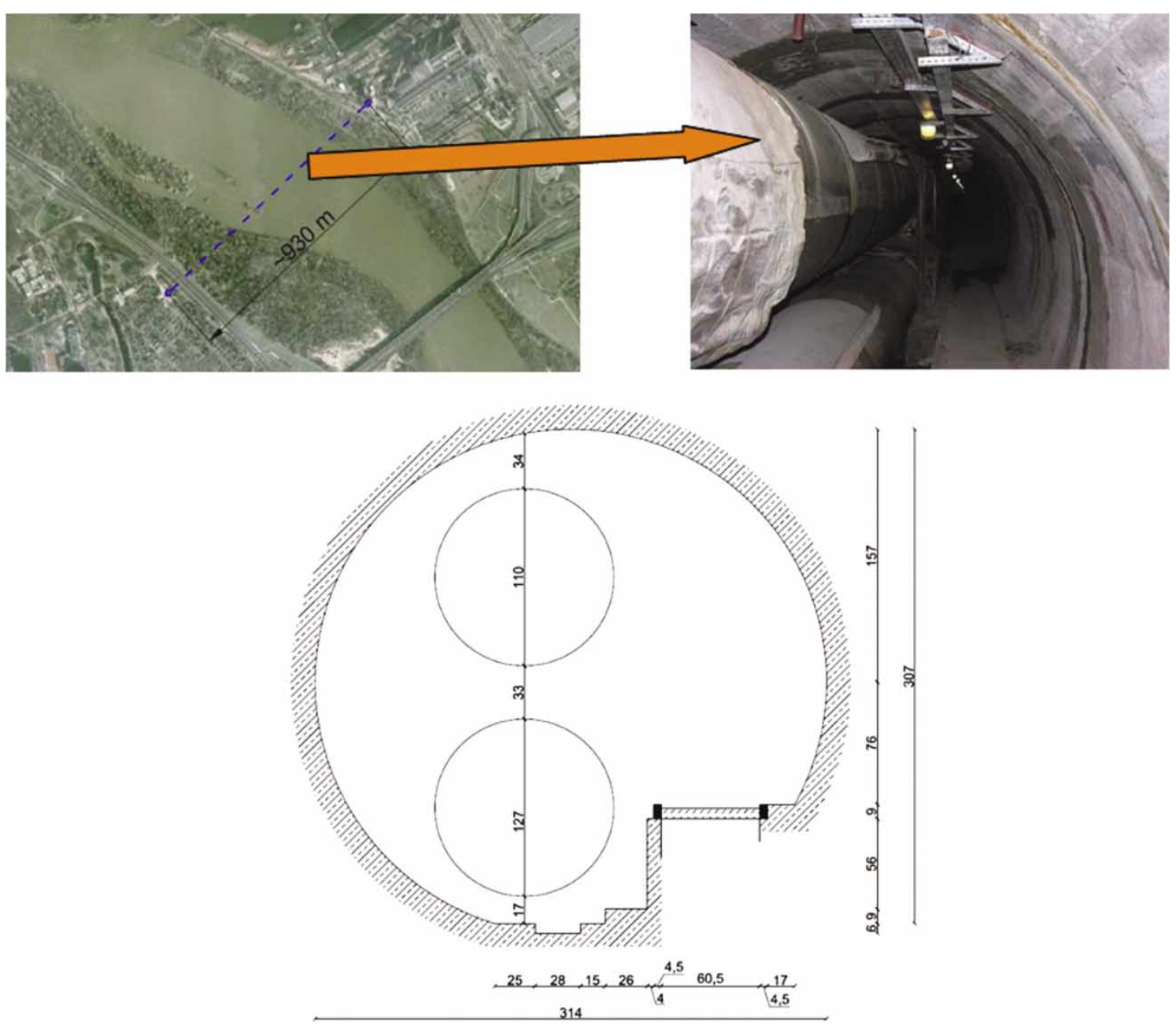

Fig. 6. Location, general view and cross section of tested tunnel under river (Gorzelańczyk et al. 2012b) 


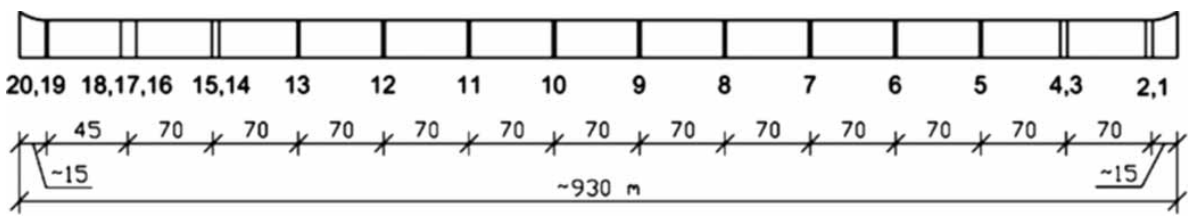

Fig. 7. Measuring places in tested tunnel

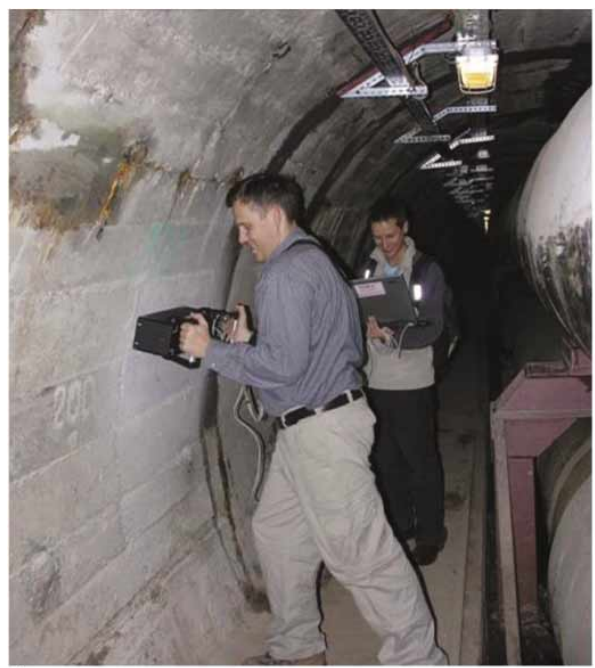

a)

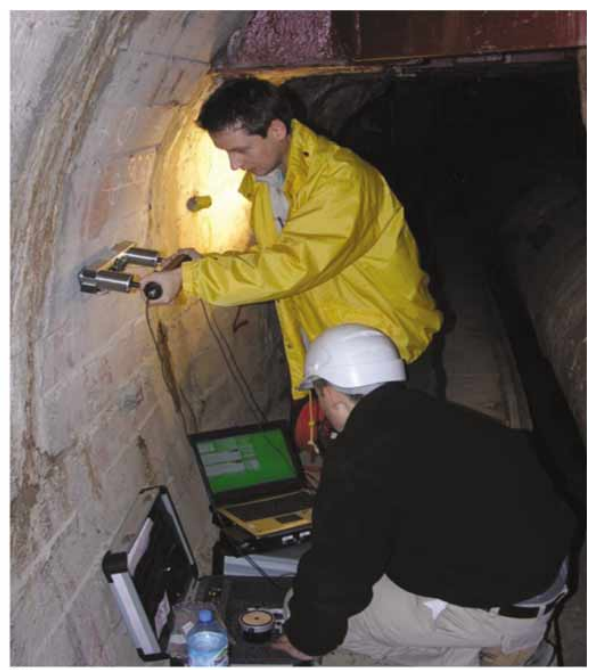

b)

Fig. 8. Testing by: (a) ultrasonic tomography technique; (b) impact-echo technique

structure with an inside diameter of about $3.5 \mathrm{~m}$ was built (manually bored) in the 1950s. The tunnel shell was made of concrete. Figure 6 shows the location of the tunnel and its general view. Today, the tunnel holds two pipes (each $900 \mathrm{~mm}$ in cross section) carrying hot water from a heat and power plant to households and a service walkway.

In connection with the planned renewal of the tunnel, the load-bearing capacity of the tunnel's concrete shell had to be determined. Since no tunnel design documents have survived, it was necessary to determine the thickness of the unilaterally accessible tunnel shell and the variation of this thickness along the tunnel length. Because of the tunnel location, no destructive tests (drilling through the tunnel shell) could be carried out. Therefore, it was decided to investigate the tunnel, using the non-destructive ultrasonic tomography and impact-echo techniques.

First, using an ultrasonic tomograph, the tunnel shell was tested in 20 randomly selected places, as

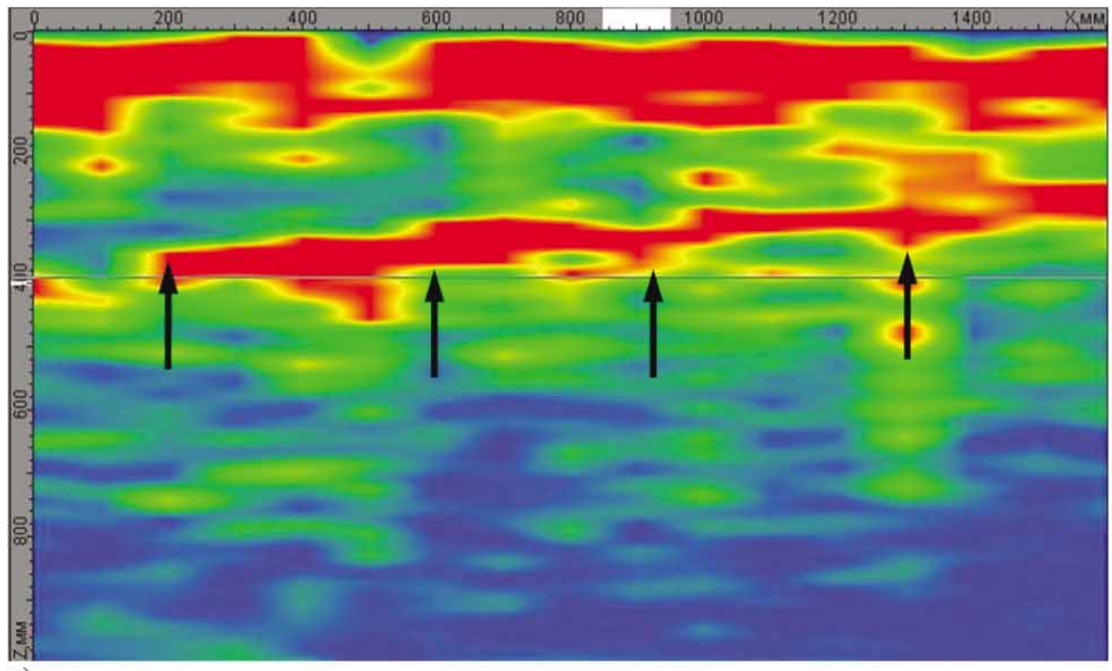

a)

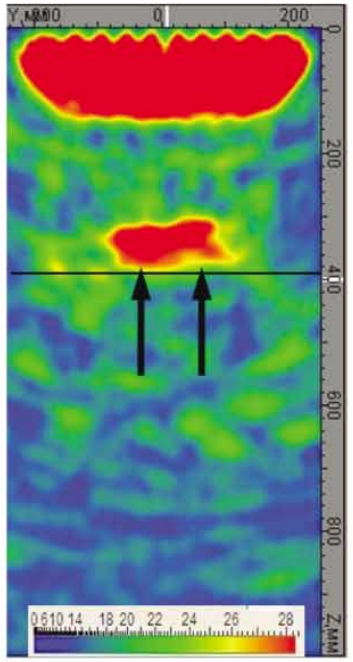

b)

Fig. 9. Exemplary results obtained in measuring place no. 1: (a) image D; (b) image B 


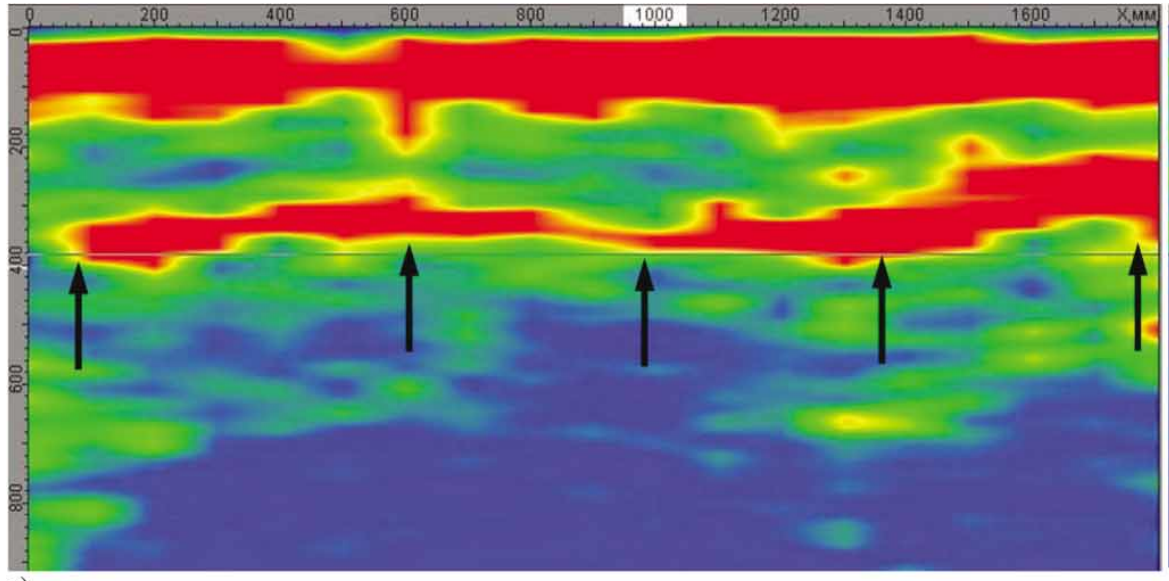

a)

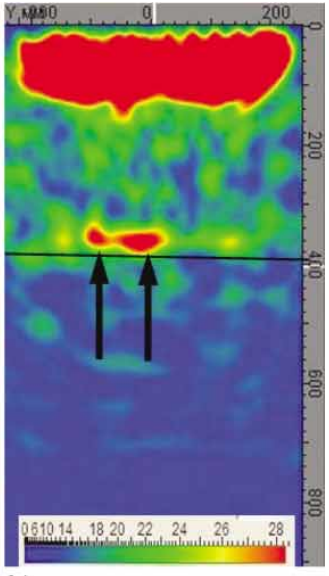

b)

Fig. 10. Exemplary results obtained in measuring place no. 7: (a) image D; (b) image B

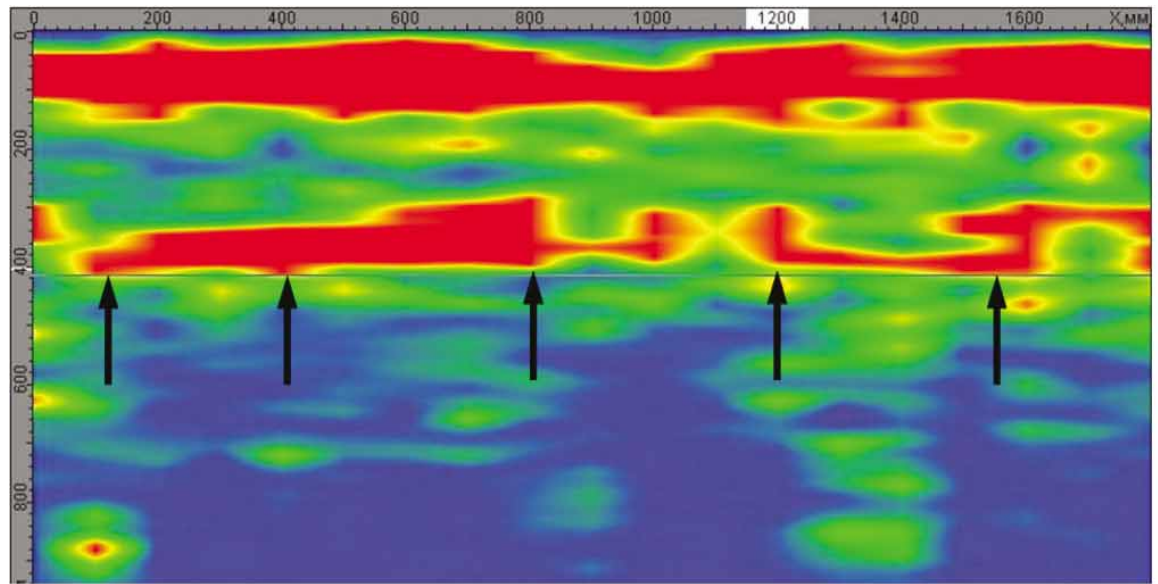

a)

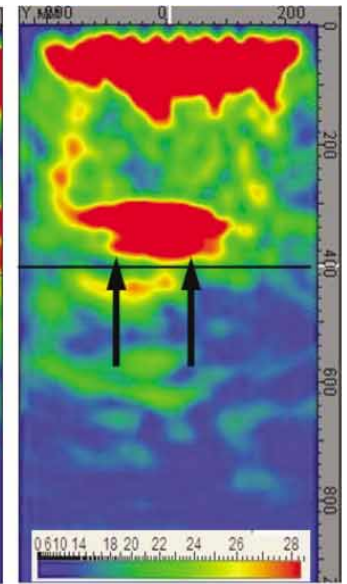

b)

Fig. 11. Exemplary results obtained in measuring place no. 19: (a) image D; (b) image B

shown in Figure 7. In each of the measuring places, tests were carried out in 500-mm-wide and $1500-\mathrm{mm}$ long measuring bands. The tests were carried out according to the proposed methodology described in Section 4, as shown in Figure 8. Altogether there were about 400 measuring points. In each of the measuring points, the ultrasonic wave velocity was measured and a preliminary analysis of the ultrasonic signals was made. After the signals were processed, the results were recorded, and the obtained images were analysed in detail to determine the thickness of the unilaterally accessible shell of the heat pipe carrying tunnel.

The images of the cross sections in each of the measuring antenna positions were collected in a threedimensional matrix table, and the three mutually

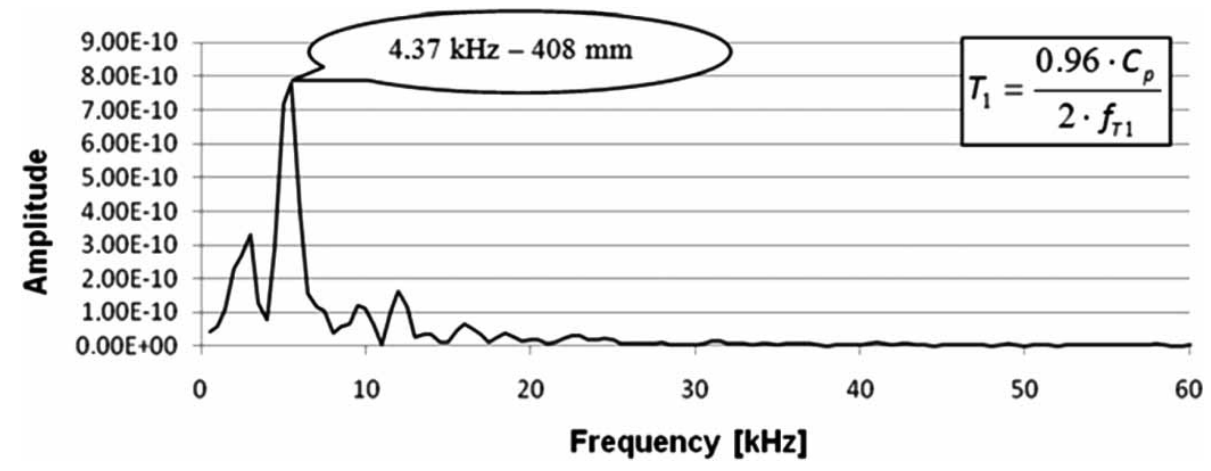

Fig. 12. Amplitude-frequency spectrum recorded in measuring place 7, using impact-echo technique 


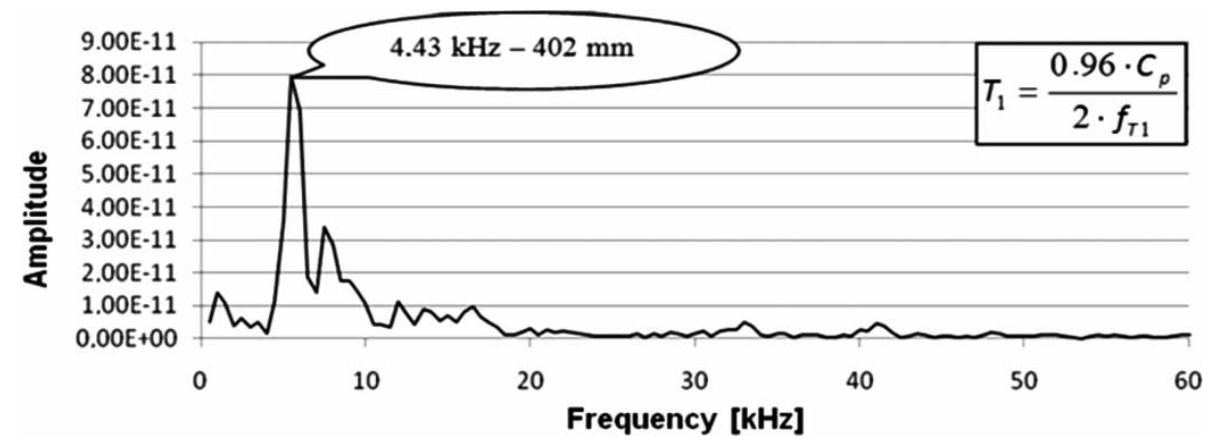

Fig. 13. Amplitude-frequency spectrum recorded in measuring place 11, using impact-echo technique

intersecting cross sections (images $\mathrm{B}, \mathrm{C}$ and $\mathrm{D}$ ) of the examined object were obtained on this basis. Figures 9-11 show exemplary images B and D obtained in measuring places, numbers 1,7 and 19. The shell thickness is marked with a solid line and, additionally, with arrows. In the bottom right corner in Figures 9b$11 \mathrm{~b}$, there is a scale of correspondence between the ultrasonic dispersion level in a point of the tested concrete tunnel shell and the colour representing it. The ultrasonic dispersion level indicates changes in the physical characteristics which are different from those of the concrete in this area. Also which may be indicative within the examined band, of a material which density is different than that one of the concrete.

In the second stage of testing, the impact-echo technique (Fig. 8b) was used to verify the determined thickness and validate the test results obtained from the ultrasonic tomograph. For this purpose, three measuring points were randomly selected in each of the measuring places marked in stage 1. Altogether there were about 60 measuring points. An elastic wave was excited in each of the measuring points and the amplitude-time spectra were recorded. The latter were converted into amplitude-frequency spectra and analysed.

Figures 12 and 13 show exemplary test results in the form elastic wave amplitude-frequency spectra recorded in measuring places, numbers 7 and 11 using the impact-echo technique.

The test results obtained using the ultrasonic tomography and impact-echo techniques showed the thickness of the concrete tunnel shell was not uniform, ranging from 389 to $416 \mathrm{~mm}$, as shown in Figure 14.

In order to verify the obtained results, a destructive test consisting of drilling through the shell in a randomly selected place was carried out. It was found that the concrete tunnel shell was $400 \mathrm{~mm}$ thick.

\section{Conclusions}

A methodology for the non-destructive identification of the thickness of unilaterally accessible concrete elements by means of the state-of-the-art acoustic

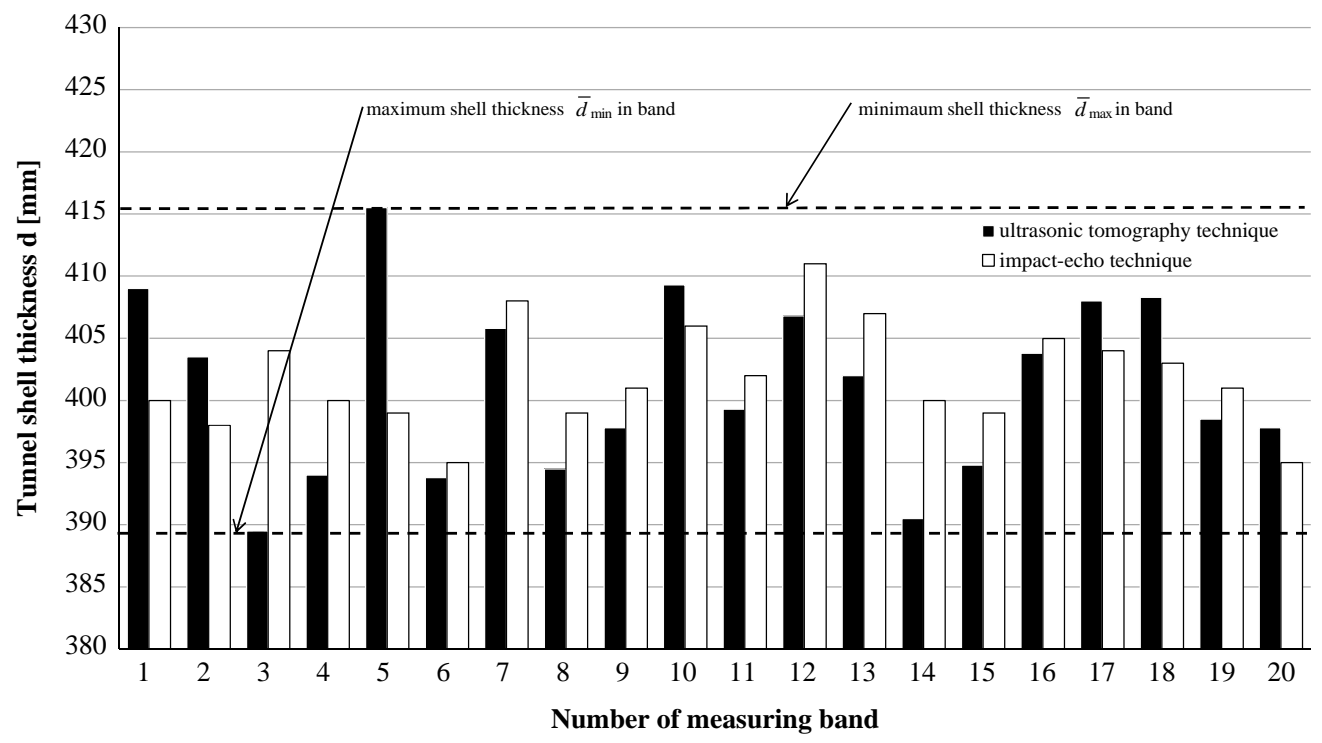

Fig. 14. Thickness of the concrete tunnel shell in particular measuring places, determined using ultrasonic tomography and impact-echo techniques 
techniques of ultrasonic tomography and impact-echo used in a comprehensive way has been presented. Since the techniques are not commonly used, they are little known. Therefore, in order to facilitate the understanding of the methodology, the presentation of the latter was preceded by a brief description of the techniques.

Two main stages in testing according to the proposed methodology are distinguished: stage 1, in which, non-destructive tests are carried out, using the ultrasonic tomography technique and stage 2 , in which, non-destructive tests are carried out, using the impact-echo technique. This can be followed by a stage in which the test results are verified by means of an exposure. Stage 3 is not always possible. If the area or length of the element to be tested is large, the nondestructive tests can be automated by mounting the testing equipment on a special scanner or robot.

An example of the practical use of the methodology, demonstrating its suitability for the non-destructive identification of the thickness of concrete elements, particularly the ones accessible from one side only, was provided. In the example, the concrete shell of a heat pipe carrying tunnel located under a river was tested using the ultrasonic tomography and impact-echo techniques. The tests were carried out according to the proposed methodology. An analysis of the test results showed that the thickness of the concrete tunnel shell was not uniform along its length, ranging from 389 to $416 \mathrm{~mm}$. It should be noted that the test results yielded by the two methods were similar. In this way, the proposed methodology has been validated.

\section{References}

ACI 228.2R-98. 1998. Nondestructive test methods for evaluation of concrete in structures. Farmington Hills, MI: American Concrete Institute (ACI). 63 p.

ASTM C1383-04. 2010. Standard test method for measuring the P-Wave speed and the thickness of concrete plates using the impact-echo method. USA: American Society for Testing And Materials (ASTM). 11 p.

Bishko, A. 2007. Improvement of imaging at small depths for acoustic tomography of reinforced concrete objects, in The 6th International Conference on NonDestructive Testing and Technical Diagnostics in Industry, 15-17 May, 2007, Moscow, Russia. Mashinostroenie -1 . Abstracts book.

Bishko, A.; Samokrutov, A. A.; Shevaldykin, V. G. 2008. Ultrasonic echo-pulse tomography of concrete using shear waves low-frequency phased antenna arrays, in The 17th World Conference on Nondestructive Testing, 25-28 October, 2008, Shanghai, China, 9.

Bundesanstalt für Straßenwesen [The Federal Highway Research Institute]. 2001. Richtlinie für die Anwendung der zerstörungsfreien Prüfung von Tunnelinnenschalen (RI-ZFP-TU) [Guidelines for the use of non-destructive testing of tunnel inner shells (RI-ZFP-
TU)]. Ausgabe 2001, Verkehrsblatt-Dokument Nr. S 1050, Verkehrsblatt-Verlag (in German).

Garbacz, A. 2005. Non-destructive assessment of repair efficiency with impact-echo and ultrasonic methods an overview, in Proc. of the 2nd International Conference on Concrete Repair, Rehabilitation and Retrofitting (ICCRRR), 21-23 November, 2005, Cape Town, South Africa, 1319-1326.

Garbacz, A.; Piotrowski, T. 2010. Application of impactecho technique to estimation of concrete floor toppings, Materialy Budowlane [Construction Materials] 9: 18-19 (in Polish).

Gorzelańczyk, T. 2011. The effect of moisture content on the failure of self-compacting concrete under compression, as assessed by means of acoustic methods, Archives of Civil and Mechanical Engineering 11(1): 45-60. http://dx.doi.org/10.1016/S1644-9665(12)60173-3

Gorzelańczyk, T. 2012. Acoustically assessed influence of air pore structure on failure of self-compacting concretes under compression, Journal of Civil Engineering and Management 18(1): 60-70. http://dx.doi.org/10.3846/13923730.2011.652982

Gorzelańczyk, T.; Hoła, J.; Sadowski, Ł.; Schabowicz, K. 2012a. Evaluation of concrete homogeneity in massive wall of hydroelectric structure by means of ultrasonic tomography technique, in The 42th International Conference on Defektoskopie, October 30 - November 1, 2012, Seč, Czech Republic.

Gorzelańczyk, T.; Hoła, J.; Schabowicz, K. 2012b. Nondestructive tests aimed at determining the thickness of the concrete shell of a heat pipe carrying tunnel, Materials Transactions 53(2): 296-302. http://dx.doi.org/10.3846/13923730.2011.65298210. 2320/matertrans.I-M2011845

Gorzelańczyk, T.; Schabowicz, K. 2012. Nondestructive testing of thickness of concrete mine lift shaft shell by means of ultrasonic tomograph, in The $42 \mathrm{th}$ International Conference on Defektoskopie, October 30 - November 1, 2012, Seč, Czech Republic.

Goszczyńska, B.; Świt, G.; Trạmpczyński, W.; Krampikowska, A.; Tworzewska, J.; Tworzewski, P. 2012. Experimental validation of concrete crack identification and location with acoustic emission method, Archives of Civil and Mechanical Engineering 12(1): 23-28. http://dx.doi.org/10.3846/13923730.2011.65298210.23 20/matertrans.I-M201184510.1016/j.acme.2012.03.004

Hoła, J.; Sadowski, Ł.; Schabowicz, K. 2008. Nondestructive evaluation of the concrete floor quality using impulse response method and impact-echo method, in Proc. of the 38th International Conference on Defektoskopie, 4-6 November, 2008, Brno, Czech Republic, 55-62.

Hoła, J.; Sadowski, Ł.; Schabowicz, K. 2011. Nondestructive identification of delaminations in concrete floor toppings with acoustic methods, Automation in Construction 20(7): 799-807. http://dx.doi.org/10.1016/j.autcon.2011.02.002

Hola, J.; Schabowicz, K. 2010. State-of-the-art non-destructive methods for diagnostic testing of building structures - anticipated development trends, Archives of 
Civil and Mechanical Engineering 10(3): 5-18. http://dx.doi.org/10.1016/S1644-9665(12)60133-2

Kozlov, V. N.; Samokrutov, A. A.; Shevaldykin, V. G. 1997. Thickness measurements and flaw detection in concrete using ultrasonic echo method, Nondestructive Testing and Evaluation 13(2): 73-84. http://dx.doi.org/10.1080/02780899708953020

Krause, M.; Milmann, B.; Niederleithinger, E. 2005. Assessment of foundation slabs with USecho in the re-use process, in Proc. of the 2nd International Conference on Concrete Repair, Rehabilitation and Retrofitting (ICCRRR), 21-23 November, 2005, Cape Town, South Africa, 525-530.

Kurz, J. H.; Stoppel, M.; Taffe, A.; Boller, C. 2012. Condition assessment of reinforced concrete structures using automated multi-sensor systems, in Proc. of the 18th World Conference on Nondestructive Testing, 1620 April, 2012, Durban, South Africa, 8 p.

Samokrutov, A. A.; Kozlov, V. N.; Shevaldykin, V. G. 2006. Ultrasonic testing of concrete objects using dry acoustic contact. Methods, instruments and possibilities, in The 5th International Conference on NonDestructive Testing and Technical Diagnostics in Industry, Moscow, Russia, 2006. Abstracts book.

Samokrutov, A. A.; Kozlov, V. N.; Shevaldykin, V. G.; Meleshko, I. A. 2002. Ultrasonic defectoscopy of concrete by means of pulse-echo technique, in The 8th European Conference for Non-Destructive Testing, 17-21 June, 2002, Barcelona, Spain. CD-ROM.
Samokrutov, A. A.; Shevaldykin, V. G. 2011. Ultrasonic tomography of metal structure using the digital focused antenna array methods, Russian Journal of Nondestructive Testing 47: 16-29. http://dx.doi.org/10.1134/S1061830911010098

Sansalone, M.; Strett, W. 1997. Impact-echo: non-destructive evaluation of concrete and masonry. Ithaca: Bullbrier Press. 339 p.

Schabowicz, K.; Hola, J. 2012. Nondestructive elastic-wave tests of foundation slab in office building, Materials Transactions 53(2): 296-302. http://dx.doi.org/10.2320/matertrans.I-M2011845

Shevaldykin, V. G.; Samokrutov, A. A.; Kozlov, V. N. 2003. Ultrasonic low-frequency short-pulse transducers with dry point contact. Development and application, in The International Symposium Non-Destructive Testing in Civil Engineering (NDT-CE), 16-19 September, 2003, Berlin, Germany, Proceedings on BB 85-CD, V66.

Stawiski, B. 2012. The heterogeneity of mechanical properties of concrete in formed constructions horizontally, Archives of Civil and Mechanical Engineering 12(1): 90-94. http://dx.doi.org/10.1016/j.acme.2012.03.006

Taffe, A.; Wiggenhauser, H. 2006. Validation for thickness measurement in civil engineering with ultrasonic echo, in Proc. of the 9th European Conference on Nondestructive Testing, September, 2006, Berlin, Germany. BB 103-CD, Th. 2.5.3.

Krzysztof SCHABOWICZ. (Ph.D., Eng) Assistant Professor in the Civil Engineering Faculty at Wrocław University of Technology. He received his Ph.D. in 2003 at Wrocław University of Technology. He is also the author and coauthor of three books, over 100 other publications as well as over 150 research and technical reports. He is a member of the Polish Association of Civil Engineers and Technicians (PZITB), a member of Polish Association of Building Mycology (PSMB). His research interests include concrete, ultrasonic tomography, impact-echo, impulse-response, GPR and other non-destructive tests, artificial intelligence. 